\title{
Institutions - Industry - Society Collaborative Learning Bring Success in Engineering Education in India
}

\author{
Arulananth T S, Pallavi Goud, Baskar M
}

\begin{abstract}
Education is one which is the continuous event which shifts the people or whole society from the dark to light. From the past few decades' education and educational methods made drastic changes in our real life. Teaching and learning process has been made enormous growth in our society. Engineering education is literally different from the general teaching learning scenario. In this world, whatever we are seeing, feeling and experiencing all except the belongings from the nature are invented or innovated by engineering education. In the beginning of the era we are unaware about engineering background also we are not finding answers for the basic questions which are raised in our day to day life like why? how? what? when and where etc. But the engineering has proven that all uncertainties to the world even though which are not close to the imagination. This growth happened in Indian engineering is not up to comparable with worldwide growth. It is very clearly indicate that till we have to improve many things in our education systems. Even though we are competent to produce multiple lakhs of engineers per year, they are not qualified for availing the job directly. Many engineers are just fit in the job but that jobs are not relevant to their qualifications. Even though we are following our own systems as well as western education system which will not satisfied our needs.
\end{abstract}

\section{INTRODUCTION}

Today, we have more educational universities and institutions and which are capable to make available enough education. But unemployment rate of last few years is too high. Nowadays, after realizing the facts of deficiencies state and central governments introduced some quality control mechanism. It is appreciable, even though these efforts also will not provide the expected outcomes. When we are analyzing, we can find that deficiencies is more in primary education. In the primary education we have to pay more attention and care. So, through this paper, we are highlights the Indian education systems and actions to be taken for the further improvements.

\section{STRATEGIES FOR SUCCESS \& RESULTS}

\section{ENGINEERING IN INDIA}

There are many strategies should be follow for the success education in our nation. Nowadays India is a big education market in the world. It is shown in following figure

Revised Manuscript Received on 14 August, 2019.

Arulananth T S, Professor, Department of Electronics and Communication Engineering, MLR Institute of Technology, Hyderabad 43, Telangana, India.(Email: arulanandh.ts@gmail.com)

PallaviGoud, Assistant Professor, Department of Electronics and Communication Engineering, MLR Institute of Technology, Hyderabad 43, Telangana, India.(Email: pallavi.goud43@gmail.com)

Baskar M, Professor, Department of Information Technology, KCG College of Technology, Karappakam, Chennai -97, Tamil Nadu, India.(Email: baashkarcse@gmail.com)

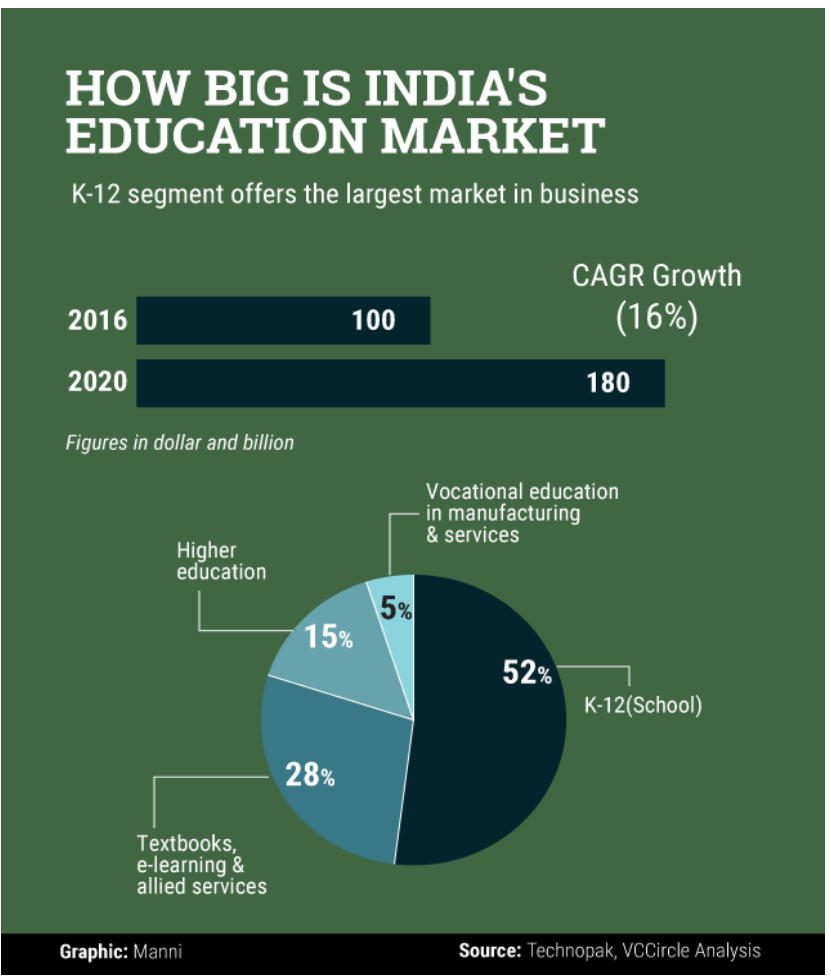

Figure:1 Education Market in India

Few of the facts are discussed in detail here.

\subsection{Meaning full Education and Education systems:}

Once we come to know that the reason of giving or getting education we can solve the problems existing in our systems. In our school education system, primary school to high school following the compulsory common syllabus for the whole class students. This will not promote the students to learn the subjects with interest because the field of interest of the students one to another. This education scenario will force the students to drop their studies in the middle. Also this will affect the future of the students; nation and it collapse the total function of the education. This was proved by much research done by earlier researchers. So, we should analyze and find the interest of students and opportunities in future in his beginning level of studies accordingly develop the curriculum structures will make success education plot form. 


\section{INSTITUTIONS - INDUSTRY - SOCIETY COLLABORATIVE LEARNING BRING SUCCESS IN ENGINEERING EDUCATION IN INDIA}

\subsection{Collaborative teaching and learning strategy:}

This society is consisting of many parts and each one are interconnected with one another and it is accept by all. These parts are doing not to be evaluating individually because we will not get the actual contribution of everyone. If everyone involving in teaching learning system it will make the system as successful. Whenever we develop a new curriculum for the further development we should consult and include the opinion of government, industries, and institutions, social and economical partners. Also we should predict the validity of this curriculum after implementing. Otherwise it will not be useful for the further development of the nation. Since, it is highly important to collaborate all above mentioned sectors in curriculum framing. The collaborative teaching learning process is like a pyramid or a triangle. The three points of the triangle only will make a real shape the growth of the nation. Framing of the curriculum is not only a matter; also the implementation is very important. Because of many challenges may be there, like lag of knowledge in implementing the new curriculum and installing adequate infrastructure for the same. To overcome the above mentioned problems by implementing laboratories and research centre with the collaboration of institute, industries and government based on the needs. Internships to students, industrial visit and industrial trainings may help to fill the gap between the curriculum and actual needs. The collaborative learning triangle is shown in figure which gives the clear information about the importance of the collaboration in teaching and learning.

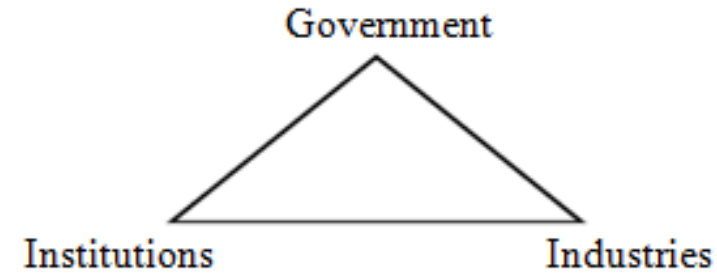

Figure 2: collaborative learning triangle

\subsection{Quality Control in Engineering Education:}

More than 10,500 Engineering educational institutions available in India based on the report published by All India Council for Technical Education (AICTE), the regulatory body for technical education in India during the period of 2017-2018 academic years. Even though we have enough quality control mechanism in our system like National Board of Accreditation (NBA), NACC, ISO etc,. and many governing bodies, but we could not produce the quality education for our students. Hence, we might accept some fault or gap in measuring mechanism. Stringent steps should be taken by the government and quality monitoring committee to improve the quality of our education systems. National Institutional Ranking Framework (NIRF) plays remarkable role in engineering quality monitoring and awarding ranging to the engineering institutions nationwide. For the quality of education we need quality teachers or mentors for the students. According to the change of curriculum faculties should be trained by experts by conducting workshops, seminar and conference etc.,. In the recruitment of faculty process also to be refine by the governments. Selection parameters to be modify according to the needs. Knowledge up gradation in most expected in teaching learning process, because the world is changing day by day. If we not able to adopt to this technical climate change in our education system, we will not grow up.

\subsection{Choice Based Education:}

Nowadays, slowly we are implementing this education principle in our nation after extensive discussion. If we are educate our students with domain specific, they will be sharp in the particular domain and they can achieve a little in their interested domain. Offering open electives and professional electives in engineering education is a first step in choice based education.

\subsection{Outcome based Education:}

It is a key educational objective in any of the studies especially in engineering education. Objectives and outcomes should be know by both teaches and learners. Witting proper course objectives is very important and it is a first step in growing engineering education.

\subsection{Examination and Evaluation process:}

Above the all an examination and an evaluation process is play the vital role in the growth of the education systems. The theoretical pattern of questions only dominated in our education system. Also all the questions are asked in the examination only lower level like remember and understand. This will discourage our students and after long period of time. Analytical or thinking level of questions will make them to involve in studies. So, the teachers should practice to set the question paper in critical level of thinking. Also we might be practice to ask a question with clarity and well defined. Formation of rubric for evaluation is very important. If we are defining the rubric correctly then the evaluation process will be simple and effective. The correct evaluation is top most priority for a teacher because the correct determination of skill of students is making the teaching learning process successful. The mark based education will make students to mark making machine only instead skill based evaluation or education will produce a skilful engineers.

\section{CONCLUSION}

The changes are unavoidable, because who one not adopted for the global change will not be sustained. We should absorb the changes happening even in the corner of the world. The education should not provide only subjects as well as competence skill, ethics of engineering, leadership quality and entrepreneurship etc. Personally i have feel that, if the engineering education may provided by their own language may help the students to understand the subjects. This effort is successful in developed countries like German, France, China, and Japan etc., but for our Indian culture it is difficult to implement because of different languages in different region. 


\section{REFERENCES}

1 Media Reports, Press Releases, Press Information Bureau, RNCOS Report, Department of Industrial Policy and Promotion (DIPP), Union Budget 2017-18

2 Crook, C. (2013). Varieties of "togetherness" in learning — and their mediation. In M. J. Baker, J. Andriessen\& S. Järvelä(Eds.) Affective Learning Together: social and emotional dimensions of collaborative learning, pp. 3351. London: Routledge.

3 Détienne, F., Barcellini, F., Baker, M., Burkhardt, J-M., \&Fréard, F. (2012). Online epistemic communities: theoretical and methodological directions for understanding knowledge co-elaboration in new digital spaces. Work: A Journal of Prevention, Assessment and Rehabilitation, 41(1), 3511-3518.

4 Dillenbourg, P. (1999b). Introduction: what do you mean by "collaborative learning"? In P. Dillenbourg (Ed.) Collaborative learning: cognitive and computational approaches, pp. 1-19. Oxford: Elsevier Science.

5 Baker, M. J. (2009). Intersubjective and intrasubjective rationalities in pedagogical debates: Realizing what one thinks. In B. Schwarz, T. Dreyfus \& R. Hershkowitz (Eds.), Transformation of Knowledge through Classroom Interaction, pp. 145-158. 